\title{
X-Band Mini Radar for Observing and Monitoring Rainfall Events
}

\author{
Marco Allegretti ${ }^{1}$, Silvano Bertoldo ${ }^{2}$, Andrea Prato ${ }^{3}$, Claudio Lucianaz ${ }^{2}$, Oscar Rorato ${ }^{2}$, \\ Riccardo Notarpietro ${ }^{2}$, Marco Gabella ${ }^{4}$ \\ ${ }^{1}$ CINFAI (Consorzio Interuniversitario per la Fisica delle Atmosfere e delle Idrosfere), \\ Politecnico di Torino, Torino, Italy \\ ${ }^{2}$ DET (Dipartimento di Elettronica e Telecomunicazioni), Politecnico di Torino, Torino, Italy \\ ${ }^{3}$ Envisens Technologies s.r.l., località Baraggino, Campus Tecnologico, Chivasso, Italy \\ ${ }^{4}$ MeteoSwiss, Locarno Monti, Switzerland \\ Email: \{marco.allegretti, silvano.bertoldo\}@polito.it
}

Received March 20, 2012; revised April 16, 2012; accepted April 25, 2012

\begin{abstract}
Quantitative precipitation estimation and rainfall monitoring based on meteorological data, potentially provides continuous, high-resolution and large-coverage data, are of high practical use: Think of hydrogeological risk management, hydroelectric power, road and tourism. Both conventional long-range radars and rain-gauges suffer from measurement errors and difficulties in precipitation estimation. For efficient monitoring operation of localized rain events of limited extension and of small basins of interest, an unrealistic extremely dense rain gauge network should be needed. Alternatively C-band or S-band meteorological long range radars are able to monitor rain fields over wide areas, however with not enough space and time resolution, and with high purchase and maintenance costs. Short-range X-band radars for rain monitoring can be a valid compromise solution between the two more common rain measurement and observation instruments. Lots of scientific efforts have already focused on radar-gauge adjustment and quantitative precipitation estimation in order to improve the radar measurement techniques. After some considerations about long range radars and gauge network, this paper presents instead some examples of how X-band mini radars can be very useful for the observation of rainfall events and how they can integrate and supplement long range radars and rain gauge networks. Three case studies are presented: A very localized and intense event, a rainfall event with high temporal and spatial variability and the employ of X-band mini radar in a mountainous region with narrow valleys. The adaptability of such radar devoted to monitor rain is demonstrated.
\end{abstract}

Keywords: X-Band Radar; Rainfall Event; Precipitation Monitoring; Rain-Gauge Comparison; High Temporal Resolution; High Spatial Resolution; Rainfall Observation

\section{Introduction}

Accurate observation of precipitations in terms of intensity and location is important for many applications: Hydro-geological risk management, hydroelectric power, road maintenance, emergency planning, and tourism are only some examples of a wider number of fields.

The most traditional method of measuring and observing rainfall using rain gauges is the less expensive but only provides punctual measurements on the ground. Other instruments such as disdrometers [1] and microwave links [2,3] provide more insight in the microstructure and the spatial average of precipitation. However, these instruments cannot capture the spatial variability of rainfall over large areas such as river catchments [4]. Moreover they are too specific and they cannot be used by simple technicians and operators of institution re- sponsible for environmental monitoring and natural hazard prevention, like for instance, Civil Protection volunteers, who often do not have the required skills to use them.

Most common C-band and S-band long range radar systems can offer an immediate way for measuring precipitation over a certain area but often their time and space resolutions are poor, especially if they are used over complex orography regions where their beam are often partially shielded by relieves, and where their performance must often be improved by some post processing techniques and long training period $[5,6]$.

After an initial brief description of high power long range radars and rain gauge networks with some of their measurements problems, X-band mini radar systems are proposed as a solution to monitor and observe rain events with a good resolution in space and time at, last but not 
least, low costs. They can be used standalone to monitoring and observing rainfall events as well as they can be a useful integration for already existing network devoted to monitoring rain.

A short paragraph is dedicated to X-band radar and gauge comparison in order to show how the proposed radar can performs a good quantitative precipitation estimation. Some case studies are then presented in order to demonstrate how it is possible and useful to use the $\mathrm{X}$-band radar in order to observe precipitation with different characteristics and how they can integrate the long range radars measurements in mountainous and complex orography terrain.

\section{Rain-Gauge Networks}

Direct measurement of rainfall at ground level can only be achieved using the common rain-gauges. However, even if modern rain-gauges are capable of providing rainfall rate in real time and with very high resolution in time, the spatial variability of rainfall is still difficult to characterize $[7,8]$.

Two major factors determine the evaluation and design of a rain gauge network: the density and locations of the rain-gauges. The choices depend on the dominant rain types and the goals to be achieved with the network. Just as an example, for flood mitigation purposes, which is the most required aim by institutions responsible for natural hazard prevention, the interpolation of rainfall at locations where no gauge is present is needed. A high density network is therefore necessary in order to perform a good interpolation. For water resources planning, instead, a low density rain-gauge network can be enough to observe long duration rainfall events.

The design of an efficient rain gauge network becomes more difficult in complex orography regions. Such environments are in fact characterized by high spatial variability of physical parameters, hard environmental and weather conditions: placing a rain gauge within a small distance from another cannot be sufficient to control a specific area: distances of few hundreds of meters may mean changing valley.

Many approaches to optimal selection of rainfall gauges taking into account their number and their location to yield greater accuracy of areal rainfall estimation have been proposed (see Cheng [9] where an extensive bibliography is listed). However each of them obviously requires the placement of a certain number of instruments and the realization of a rain gauge network could be very expensive.

Last but not least even with a well designed rain gauge network, no areal rainfall measurements are provided without a post processing algorithm to interpolate data. Interpolation does not always provide for sufficiently precise rainfall areal values.

\section{Long-Range Radar}

It is also possible to estimate rainfall amount and observe rain events evolution using long range ground based radars.

However radar systems can see the hydrometeors aloft, while we would need to know what is arriving at ground level. They give a measure of the amount of water presents inside a volume above a projected area at ground level. Obstacles, as well as earth curvature, lead to a limited horizon, allowing to see precipitation at variable height, often too far from the ground. All these difficulties increase rapidly with range from the radar location. The situation becomes obviously much more difficult in mountainous terrain, where weather echoes can only be detected at high altitudes because of beam shielding by relieves: terrain blockage combined with the small amount of precipitation during cold seasons causes inadequate radar coverage to measure precipitations especially in narrow valleys [10].

The agreement between radar and surface precipitation estimates generally decrease with increasing radar range [11]. Increasing radar sampling volume and the height of the radar beam above the ground at far ranges may increase the probability that precipitation observed aloft (which may be made by snow, ice, rain drops $\cdots$ ), is different from the one reaching the ground. This is due to evaporation, advection and vertical air motion.

Furthermore it has to be consider that precipitation is often too variable for the "coarse" resolution of longrange radars. The spatial variability of natural precipitation is so large that the radar beam is not always capable to resolve it. The under-sampling problem become increasingly severe with increasing ranges because the radar backscattering volume increases with the square of the range; therefore, at greater ranges, small but intense features of the precipitation system are blurred. This problem is known as "non-homogeneous beam filling". Some studies confirming the range dependence of long range radar behavior has been done using TRMM data [12-14].

At longer range another problem well known by radar meteorologist, tightly joined with the non homogeneous beam filling is the "beam overshooting". It is due to the decrease of vertical resolution with range and by the variability of the particles that filled the pulse, thus amplifying the influence of the horizon and Earth's curvature. It may cause no back scattering echoes even in presence of precipitation.

When very high temporal resolution is required long range radars cannot be used. In fact the time interval between map production is often too large for real time monitoring operation. Common interval of 5 minutes could be not enough to observe and track the movements of very fast rainfall cells. It is not possible to significantly shorten this time because of the large observation 
area and the relative long time of computing and antenna motion.

\section{X-Band Radars}

A good alternative and, at the same time complementary, solution between the common long range radars and the rain gauge networks can be represented by short range $\mathrm{X}$ band radars. They can provide for high space and time resolution, they operate short range and their installation cost is not so high, allowing the placement of more sensors in order to realize an optimized coverage.

In recent years, $\mathrm{X}$-band meteorological radar networks are beginning to appear; see for example, the CASA radars, very well described in a recent review article published on BAMS (Bulletin of the American Meteorological Society) [15], where an extensive bibliography is reported. X-band radars described in this paper are certainly simpler: un-coherent, pulsed, one polarization only, non Doppler, with a fixed elevation of the antenna. However they are exclusively devoted to rain measurements and able to produce one rain map in a few seconds.

$\mathrm{X}$-band mini radar used here (Figure 1), have been designed by the Remote Sensing Group (RSG) of Polytechnic of Turin, a local unit of Consorzio Interuniversitario per la Fisica delle Atmosfere e delle Idrosfere, (CINFAI). Their realization started from early ideation stages during the FORALPS ("Meteo-hydrological Forecast and Observations for improved water Resource management in the ALPS”) project in 2004 [16]. The first fully operational network of mini radar was set up in 2011 with the installations in Italy of 5 experimental mini radar, 4 of them in the Sicily Region and one of them in the Aosta Valley.

They very low cost, the lack of any special requirements for installation, practically maintenance-free and the possibility to be remotely controlled with software adjournments, make them able to conveniently cover limited areas or even just limited angular sectors. All the electronic equipments (antenna, radiofrequency unit, data processing unit, communication unit for data transmission and remote control, power unit) are placed inside the radome which is less than $2 \mathrm{~m}$ high and less than $1 \mathrm{~m}$ wide; it may be secured to any flat surface and it only needs to be connected to a power supply. All the software required to operate the dedicated applications is open source in order to allow a great reliability and flexibility in the configuration and full control of active processes and packages, as well as low costs.

The X-band radar is capable to produce an image map each 1 minute with a "virtual" resolution of $60 \mathrm{~m}$ within a range of $30 \mathrm{~km}$. Obviously only the physical range resolution is of the same order (approximately $90 \mathrm{~m}$ ) while the range resolution is much larger (at $30 \mathrm{~km}$ range it is approximately $1500 \mathrm{~m}$ ). The range of $30 \mathrm{~km}$ allows

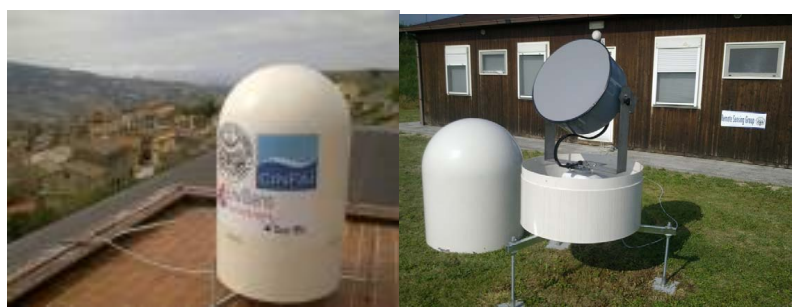

Figure 1. The $\mathrm{X}$-band mini radar with and without the radome.

to avoid some problems connected with atmospheric effects obtaining more stable back scattering echoes. A series of anti-clutter filters are also applied in order to recover, as far as possible, rain signature even in presence of clutter.

The radar maps produced by the X-band mini radar unit are transmitted to the server via a GPRS communication network (other communication systems are also allowed, if already present in the installation site). In the server, radar maps are managed by specific processing software which allows computing precipitation maps.

\section{Some X-Band Radar-Gauge Comparisons}

Aim of these papers is not to analyze systematically radar-gauge comparison, but in order to give an idea of how X-band mini radars give good rainfall measurements, some examples of comparisons with existing rain gauge network data have been analyzed.

The rain-gauges used for the comparisons are part of a regional network owned by SIAS (Servizio Informativo Agrometereologico Siciliano) and the X-band radar used are the ones installed in the Sicily region and in particular in Bisacquino (PA) and Palermo.

Rain data for comparisons have been obtained computing a temporal integration over a time interval of 1 hour, while radar data have been obtained adopting evidently the same temporal integration and a spatial integration over a $1 \mathrm{~km}^{2}$ area centered around the used rain gauge.

Rainfall amount has been obtained using an equation based on the well known article by Marshall and Palmer [17] where the radar reflectivity $\mathrm{Z}$ is related to the rainfall amount $R$ with a simple power law such as $Z=a R^{b}$, where $\mathrm{a}$ and $\mathrm{b}$ are numerical coefficient chosen on the basis of empirical experiments and analytic studies. Just to have an index for the complexity of Quantitative Precipitation Estimation (QPE) and the possible choices of such coefficients, 69 different Z-R relationships are discussed in a book of 1973 [18]. The fixed Z-R relation used here is the one proposed by Rosenfeld in 1993 [19], with $\mathrm{a}=250$ and $\mathrm{b}=1.2$, initially proposed for tropical rain but usable also for intense and persistent rain not 
only in tropical regions.

The first example shows the comparison between the radar installed in Bisacquino (PA), Italy, and the gauge in Giuliana (PA), Italy, considering a single rainfall event on 26th April 2011 (Figure 2). The second example shows the comparisons between the radar installed in Palermo and the gauge of Partinico (PA) considering the rainfall events of 18th February 2011 (Figure 3).

Both the reported examples show good agreement between radar and gauge showing that $\mathrm{X}$-band mini radar could also be used to measure precipitation.

\section{Rainfall Events Observation}

Although in Section 5 radar-gauge comparisons

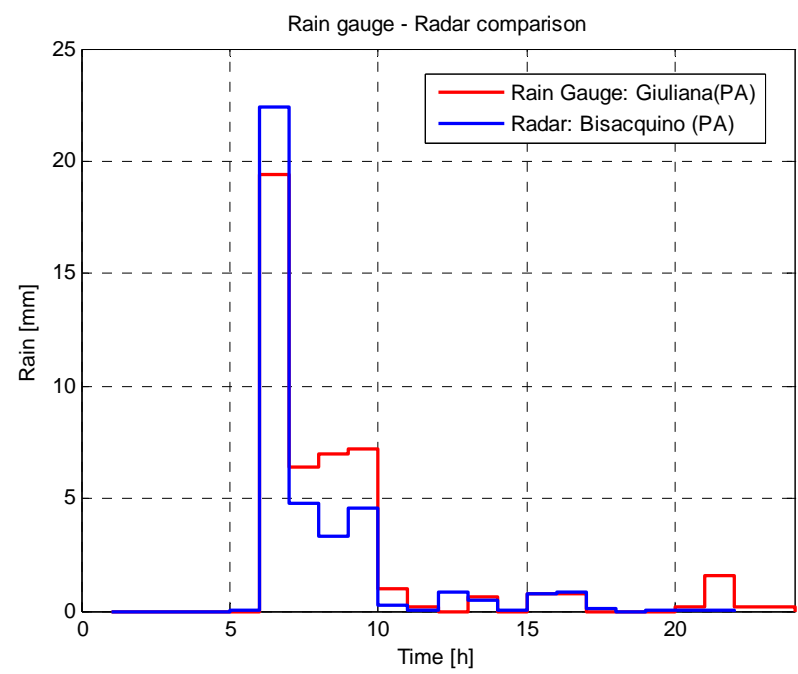

Figure 2. Comparison between the Rain Gauge of Giuliana (PA) and the $X$-band radar installed in Bisaquino (PA), 26th April 2011.

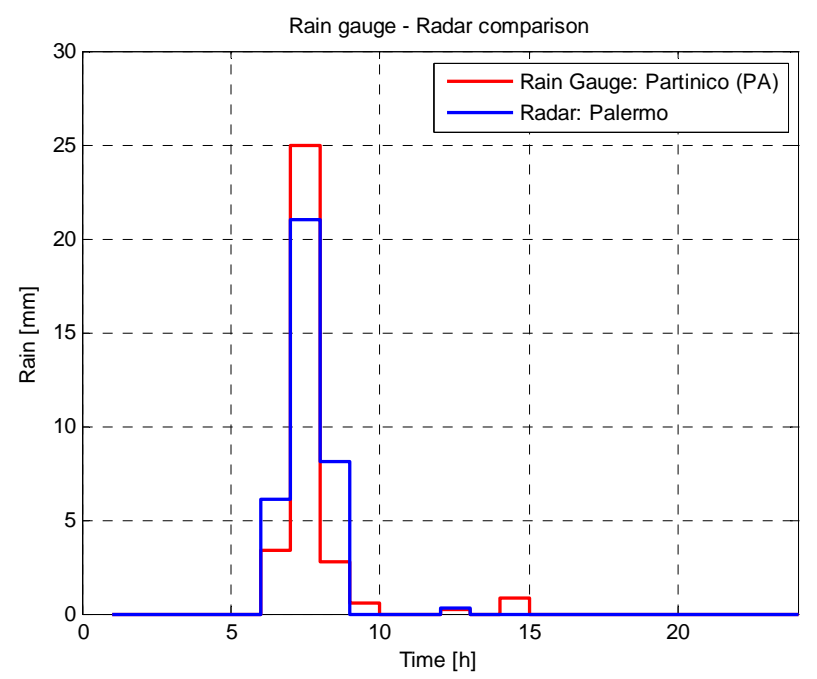

Figure 3. Comparison between the Rain Gauge of Partinico (PA) and the X-band radar installed in Palermo, 18th February 2011. show good results, confirming that $\mathrm{X}$-band mini radars can be used as instruments to measure rain rate and rainfall amounts, aim of this paper is to demonstrate how Xband mini radar are useful to observe different type of rain fields and how they can be a valuable aid in developing prevention and monitoring activities.

Institutions responsible for natural hazards preventions needs high time and space instruments with high space and time resolution to observe the evolution of a rain events. X-band mini radar are a useful tool for this purpose because their high time resolution (1 map provided each minute) allow to observe rain fields displacement, while their high spatial resolution (60 meters) allow to monitor, in a very precise way, the territory within a medium range $(30 \mathrm{~km})$ and to localize rain with sufficient precision.

Two rain events with different characteristics are here described as observed by the X-band mini weather radar installed in Palermo (PA). Both events occurred on 18th February 2011. The first occurred in the morning and was concentrated over the area around the town of Montelepre (PA). It is characterized by very intense rainfall, limited temporal duration and limited extension of the rain cell. The second, which occurred in the late afternoon, is characterized by a rapid movement of an intense rain field.

Figure 4 shows the radar. It also shows the position of the nearest rain gauge installed by Meteo Sicilia in Carini (PA) Two arrows indicates where the rain events have been observed: the red one locates the morning event, while the blue one, locates the afternoon.

\subsection{An Intense Localized Event}

Using the radar installed in Palermo it is possible to rep-

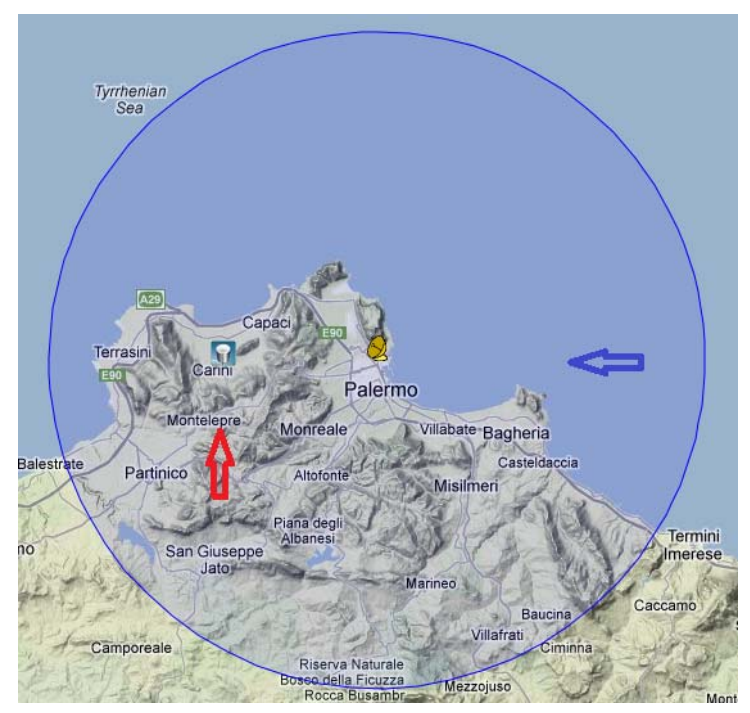

Figure 4. $\mathrm{X}$-band radar in Palermo, rain gauge and indicators of the locations of two rain events. 
resent the hourly rainfall evolution, showing maps of accumulated rain, from 4:00 - 5:00 CET to 8:00 - 7:00 UTC of 18th February 2011 (Table 1).

The rainstorm had its maximum intensity between the 6.00 UTC and the 8.00 UTC where more than $60 \mathrm{~mm}$ of rain fell over an area less than $5 \mathrm{~km}^{2}$ wide around Montelepre, The rain events was extremely fixed and it did not move from its initial position until the end of the precipitation. This fact caused flooding and intense creep of water inside the town of Montelepre which is well documented by the following photo, reported in Figure 5,

Table 1. Hourly rain accumulation map between 4.00 CET to 9.00 UTC, 18th February 2011.
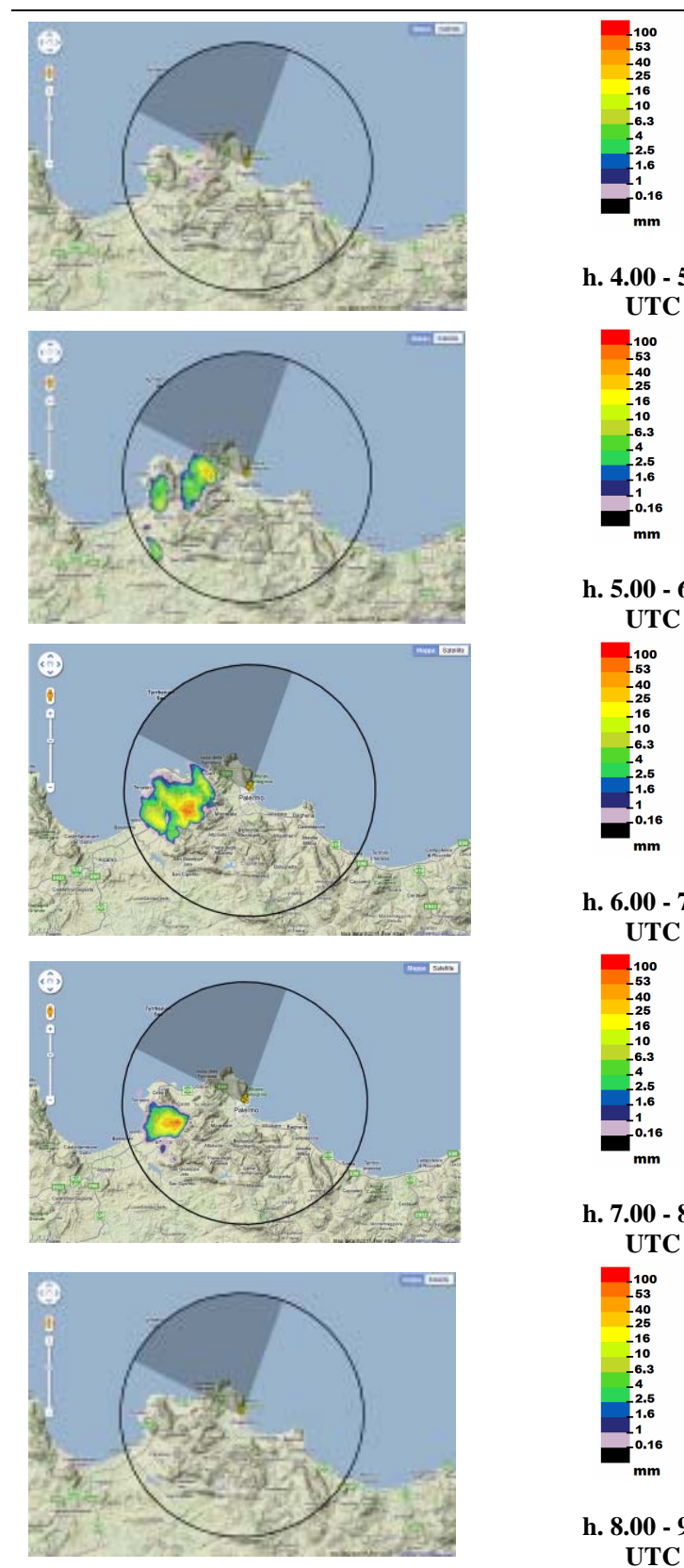

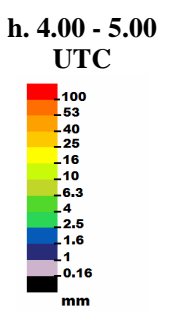

h. $5.00-6.00$ UTC

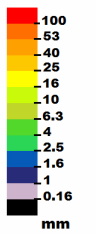

h. $6.00-7.00$ UTC

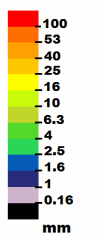

h. 7.00 - 8.00 UTC

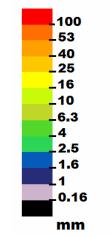

h. $8.00-9.00$ UTC

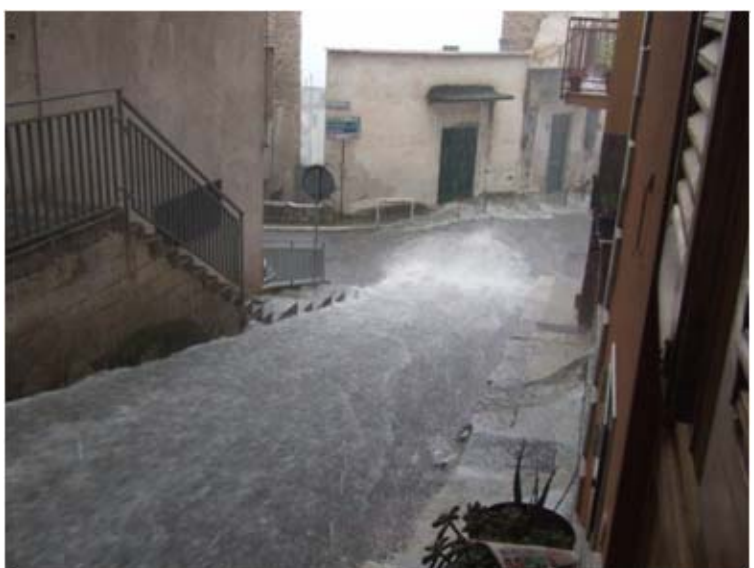

Figure 5. Intense creep of water inside the town of Montelepre.

taken, and kindly provided, by a civil protection operator while he was moving to work.

Considering the weather station installed in Carini at a distance of about $4.5 \mathrm{~km}$ from the center of Montelepre a comparison between the rainfall amount measured by rain gauge and the one measured by radar was made in order show the spatial variability of rain fields. The rain gauge performs a measurement every 5 minutes and between 6.00 and 8.00 UTC of 18th February 2011 data have been provided with regularity. The comparison was performed comparing the gauge data with the average rainfall measured by the radar on an area centered on the rain gauge with an extension of $1 \mathrm{~km}^{2}$.

It has been found that the rain gauge in Carini, between 6.00 UTC and 8.00 UTC, measured a maximum rainfall amount of only $6.5 \mathrm{~mm}$, extremely low if compared with the one fallen over Montelepre measured by the radar.

To monitor a rainfall event like the one occurred in the morning of the 18th February 2011 over the town of Montelepre only using rain gauges, a very dense network should be installed. Since the rain field had a radial extension of less than $5 \mathrm{~km}$ from its center, an unrealistic network with a gauge every 2 or $3 \mathrm{~km}$ should be provided.

\subsection{An Event with High Temporal and Spatial Variability}

Using the same X-band mini radar installed in Palermo an event with high temporal and spatial variability has been observed. The following Table 2 reports the radar maps acquired by the radar during the late afternoon of 18th February 2011. In the North-East direction it is possible to identify a rain cell which is moving very quickly from North to South. It is to be noted that the radar acquires a map every minute while here a map every 5 minute is reported. 
Table 2. Radar maps acquired by the radar in Palermo during the late afternoon of 18th February 2011.

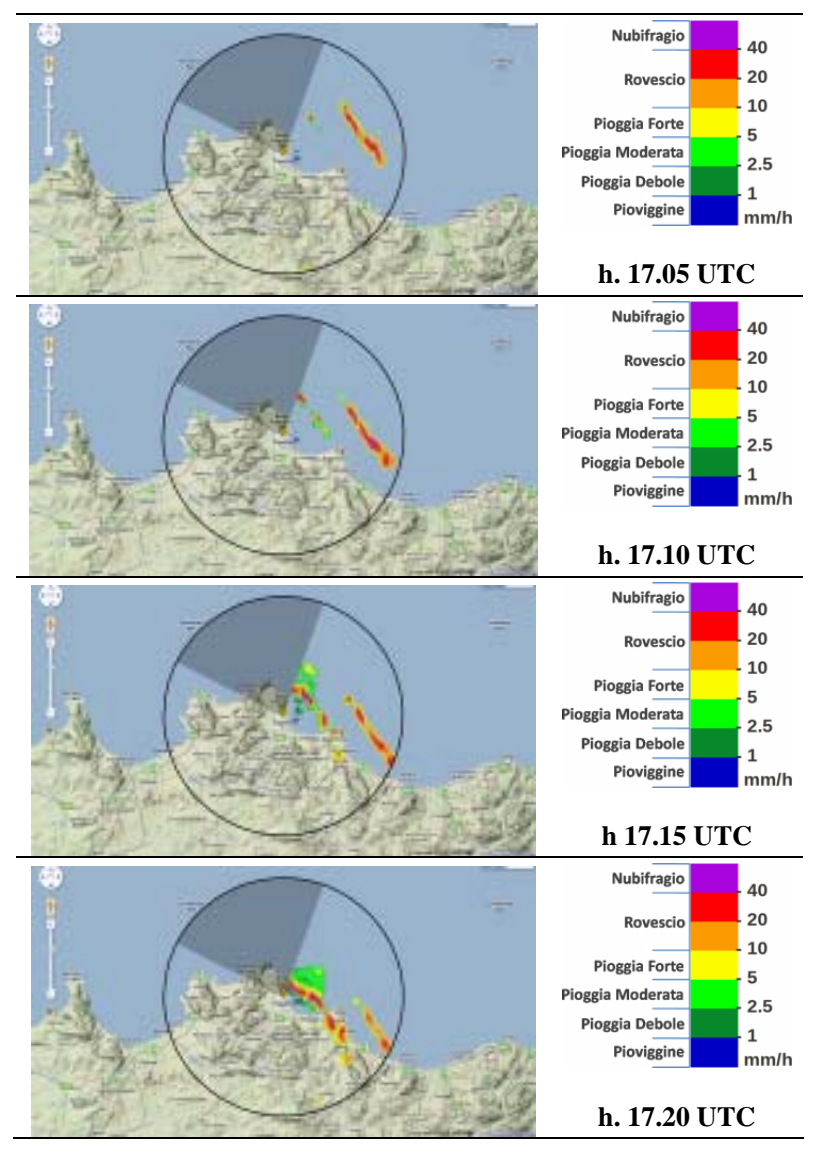

In less than 15 minutes the intense rainfall events (a rate of more than $20 \mathrm{~mm} / \mathrm{h}$ has been measured with the radar) moved at a very high velocity.

$\mathrm{X}$-band mini radars are able to detect such rain fields thanks to their high temporal resolution. This useful behavior can be applied both in observing precipitation when a particular event is already on (potentially even to control emergency procedure) and in post processing analysis to study the movement of the rain cells and to give statistical information.

Of course rain fields movement can be observed with other instruments such as satellites, but the X-band radar are easy to install and provide for good quality maps and ease of use without requiring any particular skills.

\section{Using X-Band Mini Radar in Mountainous Regions}

In mountainous terrain, precipitation is more variable both in space and time because of orographic effects and interactions of mountains with wind fields. Moreover, narrow valley surrounded by high relieves cannot be effectively monitored by any of the common long range weather radars because their beam cannot penetrate deep in the valleys.

On the other hand, also in mountainous regions, gauge network should be unrealistically dense to supplement long range radars in order to measure and observe precipitation inside the valley.

X-band mini radar could be an aid for precipitation monitoring because they can be installed directly inside the valleys, at lower altitude, so to be able to integrate the observations maps acquire by long range radar. An example of how X-band radar can supplement common C-band radar in mountainous regions is here presented.

From 3rd November 2011 to 9th November 2011 continuous, wide-spread precipitation hit all the north-western part of Italy. The analysis of the event is focused on the Aosta Valley (at the extreme North West), where an $\mathrm{X}$-band mini radar was installed during the spring of 2011. Being surrounded by high relieves (with height more than $4000 \mathrm{~m} \mathrm{MSL}$ ), the valley (which is about 500 $\mathrm{m}$ MSL) cannot be efficiently monitored by any of the surrounding long range weather radars (Dole, close to Geneva, Bric della Croce, close to Torino and Monte Lema, close to Maggiore Lake). Monte Lema was the only one able to detect some weak echoes during the period shown in Figures 6 and 7 (from 12 UTC of November 4 to 12 UTC of November 5). However, because of beam shielding by relieves combined with overshooting, the 24-hour radar-derived rainfall amounts above the Aosta Valley were heavily underestimated.

Considering the $\mathrm{X}$-band mini radar it is possible to supplement the observed precipitation fields. In fact the radar near the town of Aosta was able to detect the precipitation inside the deep valley thanks to its installation place.

The 24-hour cumulative precipitation amounts surrounding Aosta town indicates values between 16 and 25

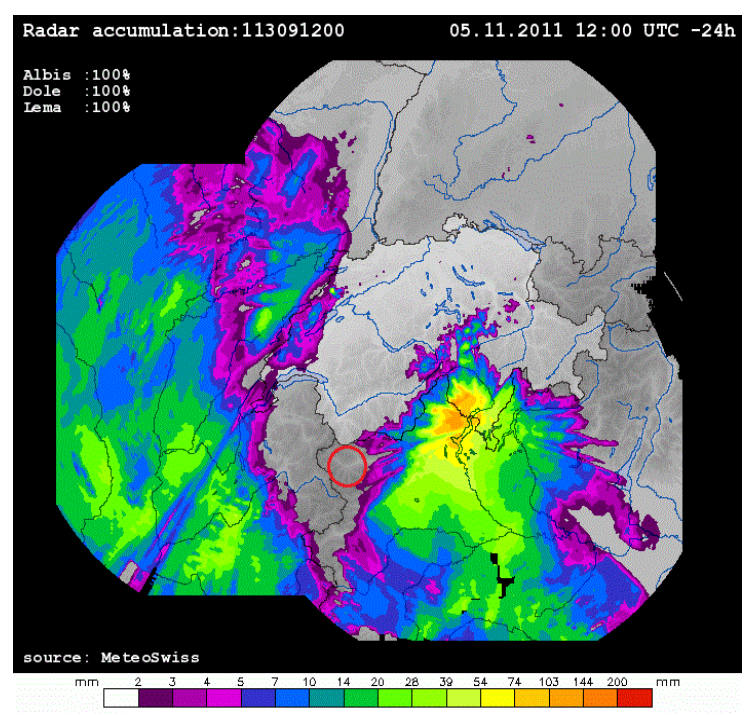

Figure 6. Long range radar map provided by Meteo Swiss. 


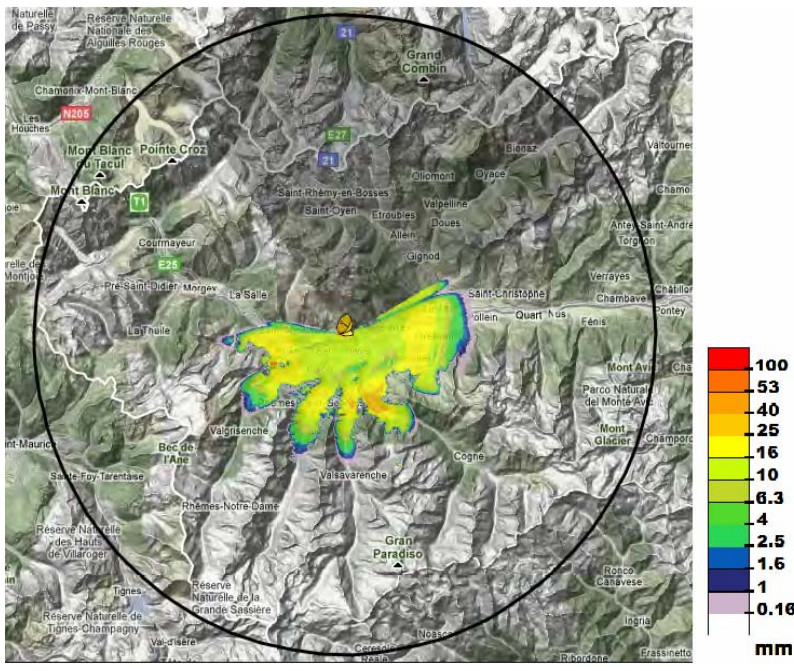

Figure 7. X-band radar map inside the Aosta Valley.

$\mathrm{mm}$ in 24 hours, with respect to the Swiss weather radar which shows amounts smaller than $2 \mathrm{~mm}$ during the same period.

\section{Conclusions}

In this paper the possibility to use small, low-cost, $\mathrm{X}$-band radars to monitor and observe rainfall events are presented.

Some case studies are also analyzed, in order to show how X-band radars can supplement existing rain-gauge networks and long range high-power radar networks commonly used today. It is shown how these shortwavelength low-cost radars are able, thanks to their high temporal and spatial resolution, to monitor portion of territory without the need to install too dense and unrealistic rain-gauge networks. Moreover they can fill a remarkable gap in observational meteorology: installing $\mathrm{X}$-band mini radars in complex orography regions it would be possible to monitor precipitation even inside deep valley.

\section{Acknowledgements}

$\mathrm{X}$-band radar presented in this paper have been installed by CINFAI (Consorzio Interuniversitario per la Fisica delle Atmosfere e delle Idrosfere, www.cinfai.it) through its local unit at DET (Dipartimento di Elettronica e Telecomunicazioni, www.det.polito.it) Polytechnic of Turin, in collaboration with Envisens Technologies s.r.l., spinoff of Polytechnic of Turin (www.envisens.com). The installations are part of cooperative projects with the Civil Protection of the Regional Province of Palermo, the Regional Civil Protection of Sicily and the Civil Protection of Aosta Valley. C-band radar map are provided by MeteoSwiss (www.meteoswiss.admin.ch). Some of the used gauge data are provided by SIAS (Servizio Informativo
Agrometreologico Siciliano. www.sias.regione. sicilia.it).

\section{REFERENCES}

[1] J. Joss and A. Waldvogel, "Raindrop Size Distribution and Sampling Size Errors," Journal of Atmospheric Sciences, Vol. 26, No. 3, 1969, pp. 566-569.

[2] H. Leijnse, R. Uijlenhoet and J. N. M. Stricker, "Rainfall Measurement Using Radio Links from Cellular Communication Networks,” Water Resources Research, Vol. 43, 2007, Article ID: W03201. doi:10.1029/2006WR005631

[3] H. Leijnse, R. Uijlenhoet and J. N. M. Stricker, "Hydrometeorological Application of a Microwave Link: 2. Precipitation,” Water Resources Research, Vol. 43, 2007, Article ID: W04417. doi:10.1029/2006WR004989

[4] C. Z. Van de Beek, H. Leijnse, J. N. M. Stricker, R. Uijlenhoet and H. W. J. Russchenberg, "Performance of High-Resolution X-Band Radar for Rainfall Measurement in The Netherlands," Hydrology and Earth System Sciences Discussion, Vol. 6, No. 5, 2009, pp. 6035-6085. doi:10.5194/hessd-6-6035-2009

[5] M. Gabella and R. Notarpietro, "Improving Operational Measurement of Precipitation Using Radar in Mountainous Terrain-Part I: Methods,” IEEE Geosciences and Remote Sensing Letters, Vol. 1, No. 2, 2004, pp. 78-83. doi:10.1109/LGRS.2003.822311

[6] M. Gabella and R. Notarpietro, "Improving Operational Measurement of Precipitation Using Radar in Mountainous Terrain-Part I: Verification and Application,” IEEE Geosciences and Remote Sensing Letters, Vol. 1, No. 2, 2004, pp. 84-89. doi:10.1109/LGRS.2003.823294

[7] G. J. Ciach, "Local Random Errors in Tipping-Bucket Rain Gauge Measurements," Journal of Atmospheric and Oceanic Technology, Vol. 20, No. 5, 2003, pp. 752-759.

[8] G. J. Ciach and W. F. Krajewski, “Analysis and Modeling of Spatial Correlation Structure of Small Scale Rainfall in Central Oklahoma," Advances in Water Resources, Vol. 29, No. 10, 2006, pp. 1450-1463. doi:10.1016/j.advwatres.2005.11.003

[9] K.-S. Cheng, Y.-C. Lin and J.-J. Liou, "Rain-Gauge Network Evaluation and Augmentation Using Geostatistics," Hydrological Processes, Vol. 22, No. 14, 2008, pp. 25542564. doi:10.1002/hyp.6851

[10] M. Gabella and G. Perona, "Simulation of the Orographic Influence on Weather Radar Using a Geometric-Optics Approach," Journal of Atmospheric and Oceanic Technology, Vol. 15, No. 6, 1998, pp. 1485-1494.

[11] J. W. Wilson and E. A. Brandles, "Radar Measurement of Rainfall-A Summary,” Bulletin American Meteorological Society, Vol. 60, No. 9, 1979, pp. 1048-1078.

[12] M. Gabella, J. Joss, S. Michaelides and G. Perona, “Range Adjustment for Ground-Based Radar, Derived with the Spaceborne TRMM Precipitation Radar,” IEEE Transaction on Geosciences and Remote Sensing, Vol. 44, No. 1, 2006, pp. 126-133. doi:10.1109/TGRS.2005.858436

[13] M. Gabella, E. Morin and R. Notarpietro, "Using TRMM Spaceborne Radar as a Reference for Compensating Ground-Based Radar Range Degradation: Methodology 
Verification Based on Rain Gauges in Israel,” Journal of Geophysical Research, Vol. 116, 2011, 14 pages. doi:10.1029/2010JD014496

[14] M. Gabella, E. Morin, R. Notarpietro and S. Michaelides, "Precipitation Field in the Southeastern Mediterranean Area as Seen by the Ku-Band Spaceborne Weather Radar and Two C-Band Ground Based Radars," Atmospheric Research, in press. doi:10.1016/j.atmosres.2011.06.001

[15] D. McLaughlin, D. Pepyne, B. Philips, J. Kurose, M. Zink, D. Westbrook, E. Lyons, E. Knapp, A. Hopf, R. Contreras, T. Djaferis, E. Insanic, S. Frazier, V. Chandasekar, F. Junyent, N. Bharadwaj, S. Cruz-Pol, K. Hondl and P. Kollias, "Short-Wavelength Technology and the Potential for Networks of Small Radar Systems,” Bulletin American Meteorological Society, Vol. 90, No. 12, 2009, pp. 1797-1817. doi:10.1175/2009BAMS2507.1
[16] R. Notarpietro, M. Zambotto, M. Gabella, S. Turso and G. Perona, "The Radar Ombrometer: A Portable, Low-Cost, Short-Range, X-band Radar for Rain Estimation within Valleys," VOLTAIRE Final Conference Joint with the 7th European Conference on Application of Meteorology (ECAM7) and the European Meteorological Society Meeting (EMS05), Utrecht, 12-16 September 2005.

[17] J. S. Marshall and W. M. Palmer, "The Distribution of Raindrops with Size,” Journal of Meteorology, Vol. 5, No. 4, 1948, pp. 165-166.

[18] L. J. Battan, "Radar Observation of the Atmosphere," University of Chicago Press, Chicago, 1973.

[19] D. Rosenfeld, D. B. Wolff and D. Atlas, "General Probability Matched Relations between Radar Reflectivity and Rain Rate,” Journal of Applied Meteorology, Vol. 32, No. 1, 1993, pp. 50-72. 